Declaration of Interest: None

References

1. Nicholson KL, Baister RL. GHB: a new and novel drug of abuse. Drug and Alcohol Dependence 2001; 63: 1.22

2. Williams $H$, Taylor R, Roberts M. Gamma-hydoryybutyrate (GHB): a new drug of misuse. IMJ 1988; $91: 56-7$.

3. Galloway GP, Frederick SL, Staggers FE, Jr Gonzales M, Stalcup SA, Smith DE. Gamma3. Galloway GP, Frederick $S L$, Staggers FE, Jr Gonzales M, Stalcup $S A$, Smith DE. Gamma-
hydroxybutyrate; an emerging drug of abuse that causes physical dependence. Addiction hydroxybutyrate;

1997; $\theta 2: 89-96$.
4. Craig K, Gomez HF, MCManus JL, Bania TC. Severe Gamma-Hydroxybutyrate withdrawal: a case report and literature review. J Emerge Med, 2000; 18: 65-70

5. Palatini P, Tedeschi L, Frison G. Dose dependent absorption and elimination of gammahydroxybutyric acid in healthy volunteers. Eur J Clinical Pharmacol 1993; 45: 353-356.

6. Dyer JE, Roth B, Hyma BA. Gamma-hydroxybutyrate withdrawal syndrome. Ann Emergency Med 2001; 37: 147-153.

7. Hechler V, Ratomponirina C, Maitre M. Gamma-hydroy-butyrate conversion into GABA induces displacement of GABA B binding that is blocked by Valproate and Ethosuximide. J Pharmacol Experimental Therapeutics 1997; 281: 753-760.

8. Hernandez $\mathrm{M}, \mathrm{Mc}$ Daniel $\mathrm{CH}$, Costanza $\mathrm{CD}$. Hernandez OJ GHB-induced delirium: a case report and review of the literature of gamma hydroxybutyric acid. Am J Peych 1998; $24: 179-83$.

9. Dyer JE. Gamma-hydroxybutyrate: a health food product producing coma and seizure like activity. Am J Emergency Med 1991; 9: 321-324.

10. Chin MY, Krueutzer RA, Dyer JE. Acute poisoning from gamma-hydroxybutyrate in California. WJ Med 1992:156: 380-384.

11. Miotto K, Darakjian J, Murray S, Zogg J, Rawson R. Gamma-hydroxybutyric acid: patterns of use, effects and withdrawal. Am J on Addict, 2001; 10: 232-41.

12. Schneir AB, Ly BT, Clark RF. A case of withdrawal from the GHB precursors gamma12. Schneir $A B$, Ly BT, Clark RF. A case of withdrawal from the GHB precursc
butyrolactone withdrawal and 1,4-butanediol. J Emerge Med, 2001: 21:31-3. 13. Sivilotti ML, Burns MJ, Aaron CK, Greenberg M J. Pentobarbital for severe gamma-
1. butyrolactone withdrawal, Ann Emergency Med 2001; 38: 660-5.

14. McDaniel C, Miotto K. Clinical manifestations and treatment of gamma-hydoxybutyric acid withdrawal: Five case studies. J Psychoactive Drugs 2001; 33: 143.9

15. Tella SR, Korupolu GR, Schindler CW, Goldberg SR. Pathophysiological and pharmacological mechanisms of acute cocaine toxicity in conscious rats. J Pharmacol Experimental Therapeutics 1992; 262: 936-946

16. Lange RA, Cigarroa RG, Flores ED. Potentiation of cocaine-induced coronary vasoconstriction by beta-adrenergic blockade. Ann Internal Med 1990; 112: 897-903.

17. Friedman J, Westlake R, Furman M. Grievous bodily harm: gamma-hydroxybutyrate abuse leading to a Wernicke-Korsakoff syndrome. Neurology, 1996; 46: 469-71

\section{Spectrum disorders survive by creativity}

Henry O'Connell is to be congratulated for putting forward such a clear exposition of evolutionary theory in psychiatry and psychology in the Irish Journal of Psychological Medicine $2004 ; 21(1): 37$.

I myself am very much an evolutionary psychiatrist and support the broad trends of evolutionary theory. Nevertheless, I see evolutionary psychiatrists' idea that the psychosis are adaptive as simply absurd. People do not produce creative work during a psychosis.

The reason that spectrum disorders have survived is that people at the edge of the spectrum are much more creative. It is not the psychosis that produced the creativity but people on the edge of the psychosis or without the full genetic input to produce a full-blown psychosis.

O'Connell is correct when he points out that workers with a Jungian background tend to suggest that evolutionary theories 'resonate with Karl Jung's ideas of the "collective unconscious"'. This is another absurd idea.

There is no doubt that the future is evolutionary psychiatry but at the moment it contains quite a number of ideas suitable for the 'shredder'.

Michael Fitzgerald, Henry Marsh Professor,

Child \& Adolescent Psychiatry, Trinity College Dublin

References:

1. O'Connell H. Evolutionary Theory in Psychiatry and Psychology. IJPM 2004;21:1-37. 2. Fitzgerald M. Autism and Creativity. Brunner Routledge, 2004.

3. Harpur J, Lawlor M, Fitzgerald M. Succeeding in College with Asperger's syndrome. IJMS, 2004;172(3):147-148

\section{Fundamentals of Psychopharmacology}

\section{Fundamentals of Psychopharmacology. Third Ed. Brian E Leonard. Wiley: Chichester, 2003. 520 pps. ISBN 0471521787.}

The author of this now familiar textbook, Brian E Leonard, is Emeritus Professor of Pharmacology at the National University of Ireland, Galway and President of the Collegium Internationale Neuro-Psychopharmacologicum (CINP). He is also a visiting professor at Maastricht.

The book has been thoroughly revised and a chapter has been added on clinical trials of psychotropic drugs. The author has a self-confessed allergy to proof reading which leaves a few mildly irritating (but intriguing) misdemeanours strewn randomly about the pages, eg reserpine was not used to treat hypotension and James (not John) Parkinson described paralysis agitans.

However, there are no major mistakes. One other, equally benign, criticism is that some of the illustrations were apparently multi-chromatic in their earlier life and their monochrome existence in the book may not do them complete justice. However, I would emphasise that these are but minor points.

This is a book well worth having. It continues to be an authoritative and readable guide to its subject. I have absolutely no difficulty in giving it a wholehearted recommendation.

Leonard's style is user-friendly and written with warmth, clarity and the right dose of scepticism. Psychiatrists of all grades should digest its contents thoroughly.

Brian O'Shea,

Consultant Psychiatrist Newcastle Hospital,

Co Wicklow, Ireland. 